\title{
Níveis de lisina digestível e zinco quelato sobre os parâmetros produtivos de poedeiras marrons ${ }^{1}$
}

\author{
Bruna Helena Carvalho Pacheco ${ }^{2}$, Messias Alves da Trindade Neto ${ }^{2}$, Ricardo de \\ Albuquerque $^{2}$, Eliana Aparecida Schammass ${ }^{3}$

\footnotetext{
1 Trabalho realizado com o apoio da Fundação de Apoio à Pesquisa do Estado de São Paulo - FAPESP.

2 Departamento de Nutrição e Produção Animal da FMVZ - USP, Campus de Pirassununga, Rua Duque de Caxias Norte, 225, CEP: 13635-900, Pirassununga, SP.

${ }^{3}$ Instituto de Zootecnia - Rua Heitor Penteado 56, Nova Odessa, SP, CEP: 13640-000.
}

RESUMO - Objetivou-se avaliar a produção de ovos em galinhas Isa Brown alimentadas com dietas com diferentes níveis de lisina digestível e zinco quelato. Utilizaram-se 720 poedeiras marrons, em dois períodos de avaliação, de 24 a 36 e de 48 a 60 semanas de idade. As dietas foram avaliadas em delineamento inteiramente casualizado, em esquema fatorial $5 \times 3$, composto de 5 níveis de lisina digestível (0,482; 0,527; 0,582; 0,644 e 0,732\%) e 3 de zinco quelato (20, 40 e 80 ppm), de modo que cada combinação foi testada em 6 repetições de 8 aves por unidade experimental. Na fase de 24 a 36 semanas de idade, houve influência da interação de lisina digestível e zinco no consumo médio diário de ração e na porcentagem de postura. Na fase de 48 a 60 semanas, a interação foi evidenciada somente no consumo médio diário de ração. O aumento da concentração de lisina digestível favoreceu o consumo de ração em todos os níveis de zinco. Em ambas as fases, a menor concentração de zinco atende às necessidades de produção das aves. O valor médio estimado de lisina digestível ideal foi de $0,732 \%$ para a fase de 24 a 36 semanas e de $0,578 \%$ para a fase de 48 a 60 semanas de idade.

Palavras-chave: aminoácido sintético, desempenho, Isa Brown, mineral, requerimento

\section{Digestible lysine and zinc chelate levels on the production variables of Brown laying hens}

\begin{abstract}
This work aimed at evaluating egg production in Isa Brown hens fed diets with different levels of digestible lysine and chelate zinc. It was used 720 brown laying hens, in two evaluation periods, from 24 to 36 and from 48 to 60 weeks of age. The diets were evaluated in a completely randomized design in a $5 \times 3$ factorial scheme composed of five levels of digestible lysine $(0.482 ; 0.527 ; 0.582 ; 0.644$ and $0.732 \%$ ) and three levels of chelate zinc (20, 40 and 80 ppm), so each combination was tested in 6 repetitions of 8 birds per experimental unit. In the phase from 24 to 36 weeks of age, there was an influence of digestible lysine and zinc on average feed intake of the ration and on laying percentage. During the phase from 48 to 60 weeks of age, the interaction was evidenced only on the average feed intake. The increase of digestible lysine concentration favored feed intake at all zinc levels. In both phases, the lowest zinc concentration meets poultry production needs. The estimated average value of ideal digestible lysine was $0.732 \%$ for the phase from 24 to 36 weeks of age and $0.578 \%$ for phase from 48 to 60 weeks of age.
\end{abstract}

Key Words: Isa brown, mineral, performance, requirement, synthetic amino acid

\section{Introdução}

A alimentação das poedeiras corresponde a mais de $65 \%$ dos custos da produção de ovos (Ribeiro et al., 2002) e a proteína é o nutriente que mais onera o custo final da ração, pondo em risco a rentabilidade das criações (Jordão Filho et al., 2006). Atualmente, com os avanços no conhecimento do metabolismo proteico e com o surgimento de novos aminoácidos sintéticos, produzidos em grande escala comercial e a preços compatíveis, é possível formular dietas que atendam melhor às exigências do animal e que possibilitem maior aproveitamento da proteína dietética, com menores custos e produção de resíduos menos nocivos ao meio ambiente (Novak et al., 2006; Schmidt et al., 2008).

$\mathrm{Na}$ formulação de dietas com vários ingredientes, deve-se considerar a fração de aminoácidos digestíveis com a finalidade de reduzir possíveis erros de suplementação de aminoácidos da dieta (Cassartelli et al., 2005). A estimativa das exigências de lisina pode ser o ponto de partida para a formulação de rações com base no conceito 
de proteína ideal, em que a lisina é o aminoácido de referência (Silva et al., 2005). Atualmente, recomenda-se 0,76\% de lisina digestível (NRC, 1994).

Devido às características de disponibilidade, fontes orgânicas ou quelatadas dos minerais têm sido utilizadas na perspectiva de aumentar a eficácia na produção. Sabe-se que os minerais orgânicos têm como principal vantagem a maior biodisponibilidade (Sechinato et al., 2004) e melhor absorção, por serem mais solúveis (Lönnerdal, 2000). A escolha entre minerais orgânicos e inorgânicos pode significar economia no custo benefício (Leeson \& Summers, 2005).

O zinco é um mineral-traço essencial para aves, pois participa na elaboração do sistema enzimático, envolvendo a síntese de proteína, o metabolismo de carboidrato e muitas outras reações bioquímicas. Deficiência severa de zinco ocasiona numerosas causas físicas e patológicas, inclusive lesões de pele, crescimento reduzido, problemas ósseos e nas juntas, enfraquecimento das penas, queda reprodutiva e redução da imunidade (Salim et al., 2008). Quando em excesso, o zinco reduz fortemente a ingestão de ração (Cotta, 2002) e, em concentração adequada, melhora a utilização da energia dietética (Namazu et al., 2008). Atualmente, o nível recomendável de zinco é de 40 ppm (NRC, 1994).

Objetivou-se com esta pesquisa avaliar o efeito dos níveis de lisina digestível e zinco na dieta sobre o desempenho produtivo de poedeiras da linhagem Isa Brown.

\section{Material e Métodos}

O experimento foi realizado no setor de avicultura do Departamento de Nutrição e Produção Animal da Faculdade de Medicina Veterinária e Zootecnia da Universidade de São Paulo, Campus de Pirassununga, São Paulo. Foram utilizadas 720 poedeiras comerciais da linhagem Isa Brown distribuídas em delineamento inteiramente casualizado, em esquema fatorial $5 \times 3$, com seis repetições de oito aves por parcela. As aves foram distribuídas duas a duas em gaiolas geminadas, construídas em arame galvanizado medindo $0,25 \times 0,40 \times 0,40 \mathrm{~m}$, dispostas em linha e providas de comedouro de chapa galvanizada e bebedouros tipo nipple com o alimento e a água fornecidos à vontade.

A primeira fase, de 24 a 36 semanas de idade, ocorreu entre novembro de 2006 e fevereiro de 2007 e a segunda, de 48 a 60 semanas de idade, entre abril e julho de 2007. As dietas foram isocalóricas ( $2.800 \mathrm{kcal} / \mathrm{kg}$ ), à base de milho e farelo de soja e foram formuladas para atender às recomendações de Rostagno et al. (2005), com inclusão de 20, 40 e 80 ppm de zinco quelato e 0,$50 ; 0,60 ; 0,70 ; 0,80$ e
1,00\% de lisina digestível. A lisina e os demais aminoácidos limitantes foram acrescidos de modo a atender às relações estabelecidas como ideais para os aminoácidos limitantes.

Ao corrigir os valores em função dos resultados analisados, determinaram-se concentrações de 137, 309 e 655 ppm de zinco quelato (35 ppm foram provenientes do milho, farelo de soja, glúten $60 \%$ e do calcário). Os níveis do aminoácido analisado pela Ajinomoto foram de 0,560; 0,612; 0,$677 ; 0,748 ; 0,851 \%$ de lisina total e, quando aplicados os índices de digestibilidade descritos por Rostagno et al. (2005) e os valores relativos para estimar a lisina digestível corrigida a partir das equações de regressão, chegaram-se às médias ponderais dos valores estimados de 0,$482 ; 0,527$; 0,582; 0,644 e 0,732\% de aminoácido digestível.

No Laboratório de Bromatologia do Departamento de Nutrição e Produção Animal da Faculdade de Medicina Veterinária e Zootecnia da Universidade de São Paulo, Campus de Pirassununga, São Paulo, foram realizadas as análises dos ingredientes e das rações (Tabela 1), segundo os procedimentos descritos pela AOAC (1984). Foram formuladas cinco rações, cada uma com um nível de lisina digestível e dividida em três porções iguais e com uma concentração mineral, totalizando 15 dietas (Tabela 1).

Os ovos de cada parcela foram coletados e contados diariamente para avaliação da produção e semanalmente foram pesados, juntamente com as sobras das rações das parcelas, para avaliação do desempenho. Avaliaram-se o consumo de ração (g), a conversão alimentar (kg/dúzia) e a produção de ovos (\%).

Os resultados obtidos para produção dos ovos foram analisados pelo programa computacional Sistema de Análises Estatísticas - SANEST (Zonta et al., 1982) e expressos nos valores analisados, com exceção das equações de regressão polinomial para os níveis de lisina digestível e zinco, que estão baseadas nos valores formulados.

\section{Resultados e Discussão}

Na fase de 24 a 36 semanas de idade, constatou-se resposta quadrática $(\mathrm{P}=0,001)$ do consumo de ração e o nível ótimo de lisina digestível foi 0,672\%, independentemente da concentração de zinco (Tabela 3). Para a conversão alimentar por dúzia de ovos, não houve interação lisina digestível e zinco, todavia a eficiência de uso dos nutrientes melhorou conforme as aves foram ficando mais velhas.

Houve efeito da interação da lisina digestível e do zinco na porcentagem de postura no período 24 a 36 semanas (Tabela 3). Nas concentrações 173 e 309 ppm de zinco, o aumento do nível de lisina coincidiu com o aumento linear 
Tabela 1 - Composição das dietas experimentais, conforme o nível de lisina

\begin{tabular}{|c|c|c|c|c|c|}
\hline \multirow[b]{2}{*}{ Ingredientes } & \multicolumn{5}{|c|}{ Lisina digestível $^{1}$} \\
\hline & 0,482 & 0,527 & 0,582 & 0,644 & 0,732 \\
\hline Milho moído & 72,391 & 71,708 & 69,737 & 67,719 & 66,237 \\
\hline Farelo de trigo & 1,594 & 0,090 & - & - & - \\
\hline Óleo de soja & - & - & 0,247 & 0,501 & 0,570 \\
\hline Lisina & - & 0,067 & 0,148 & 0,232 & 0,465 \\
\hline Treonina & 0,100 & - & 0,009 & 0,057 & 0,181 \\
\hline Triptofano & - & 0,013 & 0,028 & 0,044 & 0,087 \\
\hline Sal & 0,500 & 0,500 & 0,500 & 0,500 & 0,500 \\
\hline Calcário calcítico & 8,885 & 8,873 & 8,869 & 8,864 & 8,861 \\
\hline Fosfato bicálcico & 1,262 & 1,261 & 1,251 & 1,242 & 1,238 \\
\hline Cloreto de Colina & 0,050 & 0,050 & 0,050 & 0,050 & 0,050 \\
\hline \multicolumn{6}{|l|}{ Nutrientes calculados } \\
\hline Lisina total ${ }^{3}$ & 0,560 & 0,612 & 0,677 & 0,749 & 0,851 \\
\hline Energia metabolizável $(\mathrm{kcal} / \mathrm{kg})^{5}$ & 2800 & 2800 & 2800 & 2800 & 2800 \\
\hline Proteína $(\%)^{4}$ & 13,860 & 13,090 & 14,220 & 14,340 & 13,600 \\
\hline Cálcio $(\%)^{5}$ & 3,800 & 3,800 & 3,800 & 3,800 & 3,800 \\
\hline Fósforo disponível $(\%)^{5}$ & 0,326 & 0,326 & 0,326 & 0,326 & 0,326 \\
\hline Sódio $(\%)^{5}$ & 0,224 & 0,224 & 0,224 & 0,223 & 0,223 \\
\hline Cloro $(\%)^{5}$ & 0,334 & 0,347 & 0,362 & 0,379 & 0,424 \\
\hline Metionina + cistina digestível $(\%)^{5}$ & 0,541 & 0,546 & 0,637 & 0,728 & 0,910 \\
\hline Treonina digestível $(\%)^{5}$ & 0,504 & 0,433 & 0,462 & 0,528 & 0,660 \\
\hline Triptofano $(\%)^{5}$ & 0,116 & 0,138 & 0,161 & 0,184 & 0,230 \\
\hline Leucina digestível $(\%)^{5}$ & 1,161 & 1,213 & 1,244 & 1,272 & 1,283 \\
\hline Arginina digestível $(\%)^{5}$ & 0,693 & 0,746 & 0,790 & 0,831 & 0,853 \\
\hline
\end{tabular}

${ }^{1}$ Valor estimado com base na digestibilidade do aminoácido de cada ingrediente, segundo Rostagno et al. (2005).

2 Premix vitamínico fornece (por kg de dieta): vit. A - 7.000 UI; vit. D3 - 2000 UI; vit. E - 5 mg; vit. K - 1,6 mg; tiamina - 0,7 mg; riboflavina - 3 mg; piridoxina - 2,5 mg; vit. B12 - $8 \mathrm{mg}$; ácido nicotínico - $20 \mathrm{mg}$; pantotenato de cálcio - $5 \mathrm{mg}$; ácido fólico - 0,250 mg; biotina - 0,1 mg.

3 Análise realizada pela Ajinomoto Biolatina Indústria e Comércio Ltda.

4 Analise realizada no Laboratório de Bromatologia do Departamento de Nutrição e Produção Animal da Universidade de São Paulo.

${ }^{5}$ Concentração formulada.

Tabela 2 - Desempenho produtivo de poedeiras marrons na fase de 24 a 36 semanas de idade alimentadas com dietas com diferentes concentrações de lisina digestível e zinco quelato

\begin{tabular}{|c|c|c|c|c|c|c|c|c|c|}
\hline \multirow[t]{2}{*}{ Variável } & \multicolumn{3}{|c|}{ Zinco (ppm) } & \multicolumn{5}{|c|}{ Lisina digestível (\%) } & \multirow[t]{2}{*}{ CV $(\%)$} \\
\hline & 173 & 309 & 655 & 0,5 & 0,6 & 0,7 & 0,8 & 1,0 & \\
\hline Consumo médio de ração (g/dia) & 104,2 & 103,9 & 102,1 & 97,9 & 98,0 & 106,6 & 107,4 & 107,1 & 4,68 \\
\hline Conversão alimentar (kg/dúzia) & 1,48 & 1,48 & 1,46 & 1,50 & 1,46 & 1,48 & 1,46 & 1,45 & 5,47 \\
\hline Taxa de postura (\%) & 84,9 & 84,9 & 84,7 & 79,0 & 81,4 & 86,8 & 87,2 & 89,7 & 4,37 \\
\hline
\end{tabular}

* Efeito linear $(\mathrm{P}<0,05)$; ** Efeito quadrático $(\mathrm{P}<0,05)$.

Tabela 3 - Equações de regressão para efeitos dos níveis de lisina digestível e zinco quelatonas características de produção de poedeiras marrons na fase de 24 a 36 semanas de idade

\begin{tabular}{|c|c|c|c|}
\hline Variável & Lisina & $\mathrm{P}$ & $\mathrm{R}^{2}$ \\
\hline Consumo médio de ração (g) & $Y=53,107199+119,412055 X-65,052495 X^{2}$ & 0,001 & 83,58 \\
\hline Converso alimentar (kg/dúzia) & $Y=1,463424+0,110960 X-0,211216 X^{2}$ & 0,7 & 41,66 \\
\hline Taxa de postura (\%) & $Y=69,211550+21,693989 X$ & 0,00001 & 96,12 \\
\hline Taxa de postura, \% (zinco - 173)* & $Y=67,761408+23,886471 X$ & 0,00001 & 61,44 \\
\hline Taxa de postura, \% (zinco - 309)* & $Y=68,384683+22,892567 X$ & 0,00001 & 87,50 \\
\hline Taxa de postura, \% (zinco - 655)* & $Y=31,513124+130,394855 X-74,326187 X^{2}$ & 0,004 & 78,15 \\
\hline
\end{tabular}

$\mathrm{P}=$ probabilidade; $\mathrm{R}^{2}$ = coeficiente de determinação $(\%)$.

* Interação de lisina e zinco. 
$(\mathrm{P}<0,00001)$ da postura. Na maior concentração de zinco (655 ppm), verificou-se resposta quadrática na porcentagem de postura $(\mathrm{P}=0,004)$ ao nível de lisina digestível, o que indica limitação na resposta do aminoácido digestível. Houve efeito linear ascendente ( $\mathrm{P}=0,00001)$ do nível de lisina digestível na porcentagem de postura (Tabela 3).

Os dados encontrados na literatura para o consumo de ração superam o valor de $0,672 \%$ encontrado neste trabalho para consumo médio de 107,2 g/ave/dia e ingestão de lisina de $720 \mathrm{mg} /$ ave. Todavia, não foram realizadas análises de aminoácidos para confirmação das concentrações formuladas, de 0,76\% sugerido pelo NRC (1994) e 0,732 e 0,715\% sugerido por Sá et al. (2007) para poedeiras leves e semipesadas, respectivamente. Ao estudar níveis de lisina $(0,47$ a $0,87 \%)$ na dieta de galinhas poedeiras da linhagem Isa Babcock B-300 com 24 a 34 semanas de idade, Martinez et al. (2005) concluíram que o consumo aumentou gradualmente com a inclusão do aminoácido.

O menor consumo de ração foi observado para as poedeiras alimentadas com a ração formulada com o menor nível de lisina digestível (0,5\%), concordando com relatos de Jardim Filho et al. (2004) e Cupertino et al. (2009), que observaram menor consumo nas aves que receberam a ração como o mais baixo nível de lisina (0,6 e 0,55\%), respectivamente. Segundo Andriguetto et al. (2003), existe a possibilidade de que dietas com baixo nível de lisina ativem os mecanismos responsáveis pela redução no consumo de alimentos, como resultado do desequilíbrio aminoacídico.

Sá et al. (2007) avaliaram a exigência nutricional de lisina digestível $(0,584$ a $0,784 \%)$ em galinhas poedeiras leves e semipesadas no período de 34 a 50 semanas de idade e observaram efeito significativo da linhagem sobre a conversão alimentar, que foi melhor nas aves semipesadas. As exigências de lisina foram estimadas em 0,704 e 0,692\% para melhor conversão alimentar, correspondendo a 859 e $778 \mathrm{mg}$ de lisina/ave, para aves leves e semipesadas, respectivamente.

É possível que as exigências para postura sejam iguais ou superiores à maior concentração de lisina $(0,732 \%)$ estudada. Carvalho et al. (2003) utilizaram níveis de 0,541 a $0,861 \%$ de lisina para poedeiras no final da postura ( 44 a 55 semanas) e Schimidt et al. (2008) de 0,555 a $0,755 \%$ em dietas para poedeiras Lohmann LSL leves no segundo ciclo de produção (79 a 95 semanas de idade) e observaram efeito linear da concentração do aminoácido na taxa de postura. Jardim Filho et al. (2004), no entanto, não observaram efeito dos níveis de lisina na dieta sobre a taxa de postura de poedeiras Hy-line W 36 no período de 28 a 44 semanas de idade. O consumo da ração e a taxa de postura aumentaram de forma linear conforme as aves envelheceram.

Na fase de 48 a 60 semanas de idade, os níveis de lisina digestível $(\mathrm{P}=0,00001)$ tiveram efeito quadrático no consumo de ração (Tabela 4) e o nível estimado como ótimo foi de $0,576 \%$ para consumo médio de ração de 110,8 $\pm 0,6$ e ingestão de lisina de $638 \mathrm{mg} /$ dia (Tabela 5).

Em todo o período de 48 a 60 semanas, não houve interação dos fatores estudados para a conversão alimentar, todavia verificou-se efeito dos fatores principais. Os níveis de zinco tiveram efeito linear $(\mathrm{P}=0,04)$ ascendente sobre a conversão alimentar, que piorou com o aumento da concentração desse mineral na dieta. O nível de lisina

Tabela 4 - Desempenho produtivo de poedeiras marrons na fase de 48 a 60 semanas de idade alimentadas com dietas com cinco concentrações de lisina digestível e três de zinco quelato

\begin{tabular}{|c|c|c|c|c|c|c|c|c|c|}
\hline \multirow[t]{2}{*}{ Variável } & \multicolumn{3}{|c|}{ Zinco (ppm) } & \multicolumn{5}{|c|}{ Lisina digestível (\%) } & \multirow[t]{2}{*}{ CV (\%) } \\
\hline & 173 & 309 & 655 & 0,5 & 0,6 & 0,7 & 0,8 & 1,0 & \\
\hline Consumo médio de ração (g/dia) & 111,5 & 110,0 & 110,9 & 107,0 & 111,4 & 113,3 & 112,2 & 110,3 & 2,42 \\
\hline Taxa de postura (\%) & 83,8 & 83,0 & 81,7 & 77,0 & 82,7 & 86,7 & 85,6 & 81,9 & 5,60 \\
\hline
\end{tabular}

CV - coeficiente de variação; * Efeito linear $(\mathrm{P}<0,05)$; ** Efeito quadrático $(\mathrm{P}<0,05)$

Tabela 5 - Equações de regressão para os efeitos dos níveis de lisina digestível e zinco quelato nas características de produção de poedeiras marrons na fase de 48 a 60 semanas de idade

\begin{tabular}{|c|c|c|c|}
\hline Variável & Lisina & $\mathrm{P}$ & $\mathrm{R}^{2}$ \\
\hline Consumo médio de ração (g/dia) & $Y=69,419888+111,392784 X-70,791608 X^{2}$ & 0,00001 & 90,89 \\
\hline Conversão alimentar (kg/dúzia) & $Y=3,229405-2,854564 X+1,780804 X^{2}$ & 0,0002 & 91,45 \\
\hline Taxa de postura (\%) & $Y=17,030277+176,259717-111,548755 X^{2}$ & 0,00001 & 98,18 \\
\hline Conversão alimentar (kg/dúzia) & $\begin{array}{c}\text { Zinco } \\
\mathrm{Y}=2,106667+0,000929 \mathrm{X}\end{array}$ & 0,04 & 77,88 \\
\hline
\end{tabular}

$\mathrm{P}$ - probabilidade; $\mathrm{R}^{2}$ - coeficiente de determinação (\%).

* Interação de lisina e zinco. 
digestível teve efeito quadrático ( $\mathrm{P}=0,0002)$ na conversão alimentar e o nível estimado como ótimo foi de $0,587 \%$ para consumo de 111,0 g de ração e ingestão diária de 651 mg de lisina (Tabela 5).

Para a taxa de postura em todo período avaliado, de 48 a 60 semanas, não houve interação dos fatores estudados, mas houve influência dos fatores principais. $\mathrm{O}$ nível de lisina digestível teve efeito quadrático $(\mathrm{P}=0,00001)$ na taxa de postura, que foi melhor no valor médio estimado foi de $0,578 \%$ desse aminoácido, atingido com consumo diário de ração de 113,1 g/ave e ingestão diária de 653 mg de lisina (Tabela 5).

O nível médio de lisina digestível (0,576\%) estimado como ótimo para o consumo de ração foi menor ao sugerido pelo NRC (1994), de 0,76\%, com consumo de ração de 110,0 g e ingestão de 836 mg/dia. Jordão Filho et al. (2006) utilizaram poedeiras semipesadas da linhagem Hisex Brown (30 semanas) e não observaram influência dos níveis de lisina no consumo de ração. Resultados semelhantes foram encontrados por Penz Jr. \& Jensen (1991), Prochaska \& Carey (1993), Schutte \& Smink (1998) e Novak et al. (2004), que analisaram o consumo de ração e não observaram influência dos níveis de lisina digestível.

Essa redução no consumo de ração nos maiores níveis de lisina afeta o consumo de nutrientes e a produção de ovos e possivelmente foi ocasionada pelo efeito aminostático relatado por Macari et al. (1994), ocasionado pela ingestão de lisina em excesso. O valor médio de lisina (0,587\%) para melhor conversão alimentar foi inferior ao sugerido por Jordão Filho et al. (2006), que encontraram melhor resposta para conversão por dúzia de ovos no nível de $0,90 \%$ desse aminoácido. Resultados contrários foram descritos por Penz Jr. \& Jensen (1991), Novak et al. (2004) e Cupertino et al. (2009), que observaram que os níveis de lisina digestível não influenciaram a conversão alimentar por dúzia de ovos.

O nível de lisina (0,578\%) estimado como ótimo para porcentagem de postura nesta fase de 48 a 60 semanas diverge daquele relatado por Carvalho et al. (2003), que utilizaram níveis de 0,541 a $0,861 \%$ de lisina para poedeiras de 44 a 55 semanas, e Schimidt et al. (2008), que testaram níveis de 0,555 a $0,755 \%$ para poedeiras Lohmann LSL leves de 79 a 95 semanas e observaram efeito linear na taxa de postura. No entanto, avaliando os efeitos de diversos níveis de lisina da dieta sobre a taxa de postura de poedeiras Hy-line W36 de 28 a 44 semanas, Jardim Filho et al. (2004) não observaram efeito.

A melhora da conversão alimentar coincide com o aumento na produção de ovos, caracterizando maior eficiência no uso dos nutrientes da dieta, e esse aumento da demanda do aminoácido digestível ratifica a maior eficiência alimentar com o aumento da idade das aves até a $60^{\underline{a}}$ semana.

\section{Conclusões}

O nível ótimo de lisina para poedeiras marrons da $24 \underline{a}$ a 36 $\underline{\text { a }}$ semana de idade depende do nível de zinco para a taxa de postura, uma vez que, nos níveis de 173 e 309 ppm de zinco, o nível de lisina é igual ou superior a 0,732\%, enquanto no nível de 655 ppm desse mineral, o nível ótimo de lisina é de $0,642 \%$. Da 48aa à 60 a semana de idade, os níveis de lisina não dependem das concentrações de zinco e o nível ótimo é de $0,578 \%$ para a porcentagem de postura. O nível de 137 ppm de zinco quelato satisfaz às necessidades de desempenho das aves.

\section{Referências}

ANDRIGUETTO, J.M.; PER, Y.L.; MINARDI, I. et al. Nutrição animal. 2.ed. São Paulo: Nobel, 2003. 425p.

ASSOCIATION ON OFFICIAL ANALYTICAL CHEMISTS AOAC. Official methods of analysis. 14.ed. Arlington, VA.: Association of Official Analytical Chemists 1984. 1141p.

CARVALHO, D.C.O.; ALBINO, L.F.T.; ROSTAGNO, H.S. et al. Exigências nutricionais de lisina para poedeiras leves no período final de postura submetidas a estresse térmico. Revista Brasileira de Ciência Avícola, v.6, supl.6, p.102, 2003.

CASARTELLI, E.M.; FILARD, R.S.; JUNQUEIRA, O.M. et al. Commercial laying hen diets formulated according to different recommendations of total and digestible amino acids. Revista Brasileira de Ciência Avícola, v.7, n.3, p.177-180, 2005.

COTTA, T. Produção de pintinhos: manual prático. Viçosa, MG: Aprenda Fácil, 2002. 191p.

CUPERTINO, E.S.; GOMES, P.C.; ALBINO, L.F.T. et al. Exigência nutricional de lisina digestível para galinhas poedeiras de 54 a 70 semanas de idade. Revista Brasileira de Zootecnia, v.38, n.3, p.480-487, 2009.

JARDIM FILHO, R.M.; STRINGHINI, J.H.; NASCIMENTO, A.H. et al. Influência dos níveis de lisina sobre o desempenho de poedeiras comerciais - Hy-Line W 36. Revista Brasileira de Ciência Avícola, v.6, supl.6, p.104, 2004.

JORDÃO FILHO, J.; SILVA, J.H.V.; SILVA, E.L. et al. Exigência de lisina para poedeiras semipesadas durante o pico de postura. Revista Brasileira de Zootecnia, v.35, n.4, p.1728-1734, 2006 (supl.).

LEESON, S.; SUMMERS, J.D. Commercial poultry nutrition. 3.ed. Guelph: University Books, 2005. 398p.

LÖNNERDAL, B. Dietary factors influencing zinc absorption. Journal of Nutrition, v.130, p.1378-1383, 2000. (suppl.).

MACARI, M.; FURLAN, R.L.; GONZALES, E. Fisiologia aplicada a frangos de corte. Jaboticabal: Funep/Unesp, 1994. 296p.

MARTÍNEZ, B.F.; CRUZ, A.D.; LÓPEZ, J.L. et al. Necesidades de lisina y aminoácidos azufrados digestibles in gallinas Legorn Blancas. Veterinaria México, v.36, n.2, p.135-145, 2005.

NAMAZU, L.B.; KOBASHIGAWA, E.; ALBUQUERQUE, R. et al. Lisina digestível e zinco quelato para frangos de corte machos: desempenho e retenção de nitrogênio na fase pré-inicial. Revista Brasileira de Zootecnia, v.37, n.9, p.1634-1640, 2008.

NATIONAL RESEARCH COUNCIL - NRC. Nutrient requirements of poultry. 9.ed. Washington, D.C.: National Academy of Science, 1994. 155p.

NOVAK, C.L.; YAKOUT, H.S.; SCHEIDELER, S. The combined effects of dietary lysine and total sulfur amino acid level on egg production parameters and egg components in dekalb delta laying hens. Poultry Science, v.83, p.977-984, 2004.

NOVAK, C.L.; YAKOUT, H.S.; SCHEIDELER, S. The effect of dietary protein level and total sulfur amino acid:lysine ratio on 
egg production parameters and egg yield in Hy-Line W-98 hens. Poultry Science, v.85, p.2195-2206, 2006.

PENZ JR., A.M.; JENSEN, L.S. Influence of protein concentration, amino acid supplementation, and daily time of acess to high or low protein diets on egg weight and components in laying hens. Poultry Science, v.70, n.12, p.2460-2466, 1991.

PROCHASKA, J.F.; CAREY, J.B. Influence of dietary lysine on egg production and liquid egg composition. Poultry Science, v.72, n.10, p.186, 1993, suppl. 1. (Abstract).

RIBEIRO, M.L.G.; SILVA, J.H.V.; COSTA, F.G.P. et al. Efeito dos níveis de lisina e de proteína sobre os parâmetros de carcaças e teor de proteína dos ovos de codornas. Suplemento da Revista Brasileira de Ciência Avícola, v.4, p.68, 2002.

ROSTAGNO, H.S.; ALBINO, L.F.T.; DONZELE, J.L. et al. Tabelas brasileiras para aves e suínos: composição de alimentos e exigências nutricionais. Viçosa, MG: UFV, Departamento de Zootecnia, 2005. 186p.

SALIM, H.M.; CHEORUN, J.O.; LEE, B.D. Zinc in broiler feeding and nutrition. Avian Biology Research, v.1, n.1, p.5-8, 2008.
SÁ, L.M.; GOMES, P.C.; ROSTAGNO, H.S. et al. Exigência nutricional de lisina digestível para galinhas poedeiras no período de 34 a 50 semanas de idade. Revista Brasileira de Zootecnia, v.36, n.6, p.1829-1836, 2007.

SCHMIDT, M.; GOMES, P.C.; ROSTAGNO, H.S. et al. Exigência nutricional de lisina digestível para poedeiras leves no segundo ciclo de produção. Revista Brasileira de Zootecnia, v.37, n.6, p.1029-1035, 2008.

SCHUTTE, J.B.; SMINK, W. Requirement of the laying hen for apparent fecal digestible lysine. Poultry Science, v.77, n.5, p.697-701, 1998.

SECHINATO, A.S.; NAKADA, S.; ALBUQUERQUE, R. Efeito da suplementação dietética de microminerais orgânicos no desempenho produtivo de poedeiras comerciais. Revista Brasileira de Ciência Avícola, v.6, supl.6, p.49, 2004.

SILVA, J.H.V.; JORDÃO FILHO, J.; SILVEIRA, E.L. Por que formular dietas para poedeiras com base no conceito de proteína ideal? Revista Ave World, v.3, n.3, p.50-57, 2005.

ZONTA, E.P.; MACHADO, A.A.; SILVA JR., P. Sistema de Análise Estatística - SANEST, Registro na SEI no. 066060. Pelotas: [s.n.], 1982. 63p. 